\title{
Subclinical synovitis and enthesitis in psoriasis patients and controls by ultrasonography in Saudi Arabia; incidence of psoriatic arthritis during two years
}

\author{
Basant Elnady ${ }^{1,2}$ - Nashwa K. El Shaarawy ${ }^{3,4}$ - Noha Mohammed Dawoud ${ }^{5,6} \cdot$ Tohamy Elkhouly $^{7,8}$. \\ Dalia El-Sayed Desouky ${ }^{9,10} \cdot$ Eman Nabil ElShafey ${ }^{5,11}$ • Mohamed S. El Husseiny ${ }^{12,13}$ • Johannes J. Rasker ${ }^{14}$
}

Received: 8 November 2018 / Revised: 12 January 2019 / Accepted: 16 January 2019 / Published online: 12 February 2019

(C) The Author(s) 2019

\begin{abstract}
Objective To evaluate ultrasonographic subclinical inflammatory synovitis and enthesitis in psoriasis patients, without clinical arthritis or enthesitis compared with healthy controls, with a 2-year follow-up to study the associated incidence of psoriatic arthritis (PsA).

Methods A total of 109 consecutive psoriasis vulgaris patients without clinical signs of PsA and 90 healthy controls were included from two tertiary medical centers. Subjects underwent dermatological examination, PASI score evaluation for severity of psoriasis, musculoskeletal examination using 68/66 joints count for tenderness and swollen joints. Patients were assessed for CRP, musculoskeletal ultrasound (MSUS) in the form of grayscale ultrasound (GSUS), and power Doppler ultrasound (PDUS) for eight entheses and 34 joints to detect MSUS subclinical enthesitis and synovitis. All patients were followed-up for 2 years to detect evolving PsA.

Results Subclinical enthesitis and synovitis were detected in $39.5 \%$ of psoriasis patients and $10 \%$ of controls $(P<0.001)$. CRP was significantly higher in psoriasis patients with MSUS manifestations $(P<0.01)$. PDUS and GSUS subclinical synovitis and/ or enthesitis were detected at least in one site in psoriatic patients more than in controls $(P<0.05)$. During a 2-year follow-up of patients, the annual PsA incidence was 4.3\%. Psoriasis patients who developed PsA showed a higher prevalence of baseline enthesitis, higher PDUS and GSUS synovitis scores, and higher baseline CRP level than those who did not develop PsA.

Conclusions MSUS subclinical synovitis and enthesitis are quite common in psoriasis patients. The incidence of PsA in Saudi's psoriasis patients was slightly higher than worldwide reports. Subclinical enthesitis, PDUS, and GSUS synovitis could predict PsA development.
\end{abstract}

Keywords Incidence $\cdot$ Psoriatic arthritis $\cdot$ Synovitis $\cdot$ Ultrasound

Johannes J. Rasker

j.j.rasker@utwente.nl

1 Department of Rheumatology, Rehabilitation and Physical Medicine, Benha University, Benha, Egypt

2 Department of Rheumatology, Al Hada Armed Forces Hospital, Taif, Kingdom of Saudi Arabia

3 Department of Rheumatology, Rehabilitation and Physical Medicine, Suez Canal University, Ismailia, Egypt

4 Department of Rheumatology, United Doctor Hospital, Jeddah, Kingdom of Saudi Arabia

5 Department of Dermatology, Andrology and STDs, Menoufia University, Shibin El Kom, Egypt

6 Department of Dermatology, Al Hada Armed Forces Hospital, Taif, Kingdom of Saudi Arabia

7 Department of Radiology, Benha University, Benha, Egypt
8 Department of Radiology, Al Hada Armed Forces Hospital, Taif, Kingdom of Saudi Arabia

9 Department of Public Health and Community Medicine, Menoufia University, Shibin El Kom, Egypt

10 Department of Family and Community Medicine, Taif University KSA, Ta'if, Saudi Arabia

11 Department of Dermatology, United Doctor Hospital, Jeddah, Kingdom of Saudi Arabia

12 Department of Radiology National Research Centre, Cairo, Egypt

13 Department of Radiology United Doctor Hospital, Jeddah, Kingdom of Saudi Arabia

14 Department Psychology, Health and Technology, Faculty of Behavioral, Management and Social sciences, University of Twente, PO box 217, 7500 AE Enschede, The Netherlands 


\section{Introduction}

Psoriasis is a quite common chronic, inflammatory immune-mediated skin disease affecting about $2 \%$ of the population [1]. Psoriatic arthritis (PsA) is a member of the spondylarthropathy family and may be defined as an inflammatory arthropathy associated with psoriasis and usually negative for rheumatoid factor [2]. Wright and Moll described the classification criteria in 1973 [3]. The prevalence of psoriasis varies widely among populations in Norway and Russia; $5-10 \%$ of the population is affected while $0-0.3 \%$ of the West Africans or native Americans are affected [4]. To our knowledge, no prevalence data in Arab countries are available. One study in Eastern Saudi Arabia showed that $5.3 \%$ of the new cases in a tertiary dermatology clinic had psoriasis, but no prevalence data are available [5].

Among psoriasis patients, 7-42\% may develop PsA [6, 7]. The prevalence of PsA ranged between 0.056 and $0.28 \%$ in the USA in a large population study [8].

Once the diagnosis of PsA has been established, treatment should be started to alleviate signs and symptoms, prevent future joint damage, and maximize quality of life (QOL) to improve the outcomes [9]. Development of diagnostic and monitoring tools help to establish diagnosis for early disease control. Cutaneous manifestations of psoriasis mostly precede the onset of arthritis by an average of 10 years; however, in up to $14-21 \%$ of patients, arthritis develops prior to the occurrence of skin psoriasis [10-13]. Several studies in psoriasis patients without clinical arthritis showed that a percentage had subclinical enthesopathy and synovitis. MRI is considered one of the sensitive radiological modalities. It has shown to be more sensitive than clinical examination in detecting synovitis and enthesitis, but unfortunately, MRI is not widely used in clinical practice due to its high cost and limited availability [14]. With musculoskeletal ultrasound (MSUS), synovitis and enthesitis can also be detected, differentiating between inflammatory and non-inflammatory arthritis [10]. Emad et al. revealed subclinical synovitis, enthesitis, and bone marrow edema changes in 48 psoriasis patients without psoriatic arthritis manifestations using MRI. In almost all (90/96), knees, bone marrow edema, enthesitis, and/or synovitis was found [14].

The current multicenter study aimed to assess the presence of subclinical synovitis and enthesitis in psoriasis patients free from clinical arthritis or enthesitis, in comparison with healthy controls, followed by prospective follow-up of psoriasis patients to assess PsA incidence and study possible relation to baseline findings.

\section{Methods}

The study design was multicenter case-control study followed by prospective cohort study.

\section{Study population}

One hundred nine consecutive psoriasis patients without clinical evidence of synovitis and/or enthesitis at the time of clinical examination were enrolled in our study. Ninety age- and sex-matched healthy subjects were collected from the healthy hospital workers and included as a control group. The patients and controls were collected from two tertiary Saudi medical centers (Al Hada Armed Forces Hospital, Taif, and United Doctors Hospital, Jeddah).

Inclusion criteria Inclusion criteria were age $>18$ years and patients with plaque psoriasis, nail psoriasis, and/or scalp psoriasis.

Exclusion criteria Exclusion criteria were a past history of musculoskeletal diseases, arthritis, enthesitis, tenosynovitis, medications other than topical treatments for psoriasis in the previous 6 weeks, any history of conventional or biologic DMARDs, history of autoimmune rheumatic disease, or any patients who fulfill the PsA classification criteria [15]. Patients and controls underwent detailed clinical assessment of the joints by a rheumatologist using 68/ 66 joint count for swelling and tenderness [16], or enthesitis at 13 entheses using the Maastricht Ankylosing Spondylitis Enthesis Score (MASES) [17]; any participant with tender, swollen joints, or enthesitis was excluded from the study. Patients with positive anti-nuclear antibodies (ANA), rheumatoid factor or anti-cyclic citrullinated peptide (CCP), and those doing sports activity within the last 2 weeks were also excluded from our study.

Clinical evaluation and assessment At baseline, a detailed medical history was taken and complete clinical examination was performed by an expert dermatologist and rheumatologist.

Dermatological assessment The severity of psoriasis was assessed using the psoriasis area severity index (PASI) score [18]. The extent of psoriasis is scored separately in four body regions (head, trunk, arms, and legs) and then the sum is calculated. Psoriasis nail involvement was also documented. For each section, the percentage of affected skin area is estimated and then transformed into a grade from 0 to $6: 0 \%$ of the affected area $(0) ;<10 \%$ of the affected area (1); 10-29\% of the affected area (2); 30$49 \%$ of the affected area (3); 50-69\% of the affected area (4); $70-89 \%$ of the affected area (5); and $90-100 \%$ of the affected area (6).

Within each section, clinical signs of psoriasis were recorded (erythema, induration, and scaling) and given a grade from 0 to 4 . Then, those grades were multiplied by the score of that section and its weight ( 0.1 for the head, 0.2 for arms, 0.3 for body, and 0.4 for legs). 
Laboratory Measurement of C-reactive protein (CRP) was done using the enzyme-linked immunosorbent assay (ELISA) technique which was considered positive if $>5 \mathrm{mg} /$ 1. Clinical assessment was evaluated on the same day as the musculoskeletal ultrasound (MSUS) examination.

\section{Musculoskeletal ultrasound protocol and acquisition MSUS} evaluation was done by two expert radiologists blinded to the clinical assessment findings although they were able to see possible skin lesions near the scanned joints. Systemic multiplanar MSUS examination was performed for both psoriatic patients and controls. Grayscale (GSUS) and power Doppler (PDUS) at 34 joints levels, eight entheses were performed with the same scanner (Philips CX50) using two multi-frequency linear transducers (6 to $18 \mathrm{MHz}$ and 5 to $12 \mathrm{MHz}$ ) and Philips L15-7Io Compact Linear Array (Hockey Stick) 23MM Transducer (15-7 MHz). The following joints were investigated: bilateral wrists, metacarpophalangeals (MCPs), proximal interphalangeals (PIPs), distal interphalangeals (DIPs), thumb interphalangeal joint (IPJ), knees, and ankles. Each joint was scanned in transverse and longitudinal planes. GSUS synovitis was defined as the presence of abnormal hypoechoic/anechoic intra-articular area with synovial effusion and/or synovial thickening which may exhibit PDUS signals. The following eight bilateral entheses sites were assessed for enthesopathy: medial and lateral epicondyles, proximal and distal patellar tendons, Achilles tendon, and plantar fascia. Enthesitis is defined as abnormal hypoechoic tendon insertion, calcification, enthesophytes, or erosion which may show PDUS signals of active enthesitis [19].

\section{Ultrasound findings interpretation}

GSUS for synovial thickening with or without effusion and PDUS signals for actively inflamed synovium were subjectively graded on a semi-quantitative scale from 0 to 3 (Fig. 1 and Table 1) [20].

Doppler Scoring of Synovitis Signal was graded on a semiquantitative scale from 0 to 3 (Table 2).

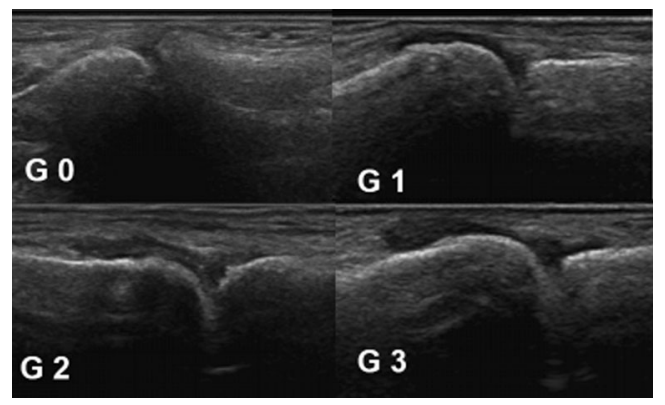

Fig. 1 Demonstration of MSUS joint effusion grading in MCP joints G0, grade 0: no effusion; G1, grade 1: minimal effusion; G2, grade 2: moderate effusion; G3, grade 3: marked effusion
Table 1 Interpretation of ultrasound findings: grayscale (GSUS) for synovial thickening with or without effusion were subjectively graded on a semi-quantitative scale from 0 to 3

$\begin{array}{ll}\text { Grade } 0 & \text { No anechoic effusion or hypoechoic synovial thickening. } \\ \text { Grade 1 } & \begin{array}{c}\text { Minimal anechoic for synovial fluid or hypoechoic } \\ \text { synovial thickening that fills the periarticular } \\ \text { bone angle without overt bulging over the line } \\ \text { linking the tops of both bones. }\end{array} \\ \text { Grade 2 } & \begin{array}{c}\text { Moderate anechoic for synovial fluid not distending } \\ \text { the joint capsule, hypoechoic synovial thickening } \\ \text { obviously bulging over the line between the tops } \\ \text { of the periarticular bones, however, it does not } \\ \text { extent along the bony diaphysis. } \\ \text { Marked anechoic for synovial fluid distending the joint } \\ \text { capsule, hypoechoic synovial thickening obviously } \\ \text { bulging over the line between the tops of the periarticular } \\ \text { bones, which extend along at least one of the bony } \\ \text { diaphysis. GSUS images of the subjectively graded } \\ \text { semi-quantitative scale of effusion in psoriatic } \\ \text { patients are shown in. }\end{array}\end{array}$

Entheses were assessed for the presence of GSUS enthesitis (tendon-thickening hypoechogenicity, bony irregularities, enthesophytes, erosion) with or without PDUS signals [10, 19].

Power Doppler frequency was set lower for the deep studied structures, and higher for superficial structures and small joints, with low filter. The color gain was adjusted just lower to the level that causes the appearance of noise artifacts [21].

Prospective follow-up Psoriasis patients with or without MSUS findings were followed up clinically every 3 months by two expert rheumatologists over 2 years, for signs and symptoms of PsA diagnosis according to the classification criteria for Psoriatic Arthritis (CASPAR) [15] and study its relation to baseline demographic, MSUS, and laboratory variables.

Data analysis Data were coded, tabulated, and analyzed using SPSS version 20 (Armonk, NY: IBM Corp.). Descriptive data were expressed as numbers and percentages and chi-squared tests $\left(\chi^{2}\right)$ and were applied to test the relationship between variables. Quantitative data were expressed as mean and

Table 2 Power Doppler (PDUS) signals for actively inflamed synovium were subjectively graded on a semi-quantitative scale from 0 to 3

\begin{tabular}{|c|c|}
\hline Grade 0 & Absence or minimal flow. \\
\hline Grade 1 & $\begin{array}{l}\text { Mild: up to } 3 \text { single spot vessel signals or up } \\
\text { to } 2 \text { confluent spots or } 1 \text { confluent spot plus } \\
\text { up to } 2 \text { single spots. }\end{array}$ \\
\hline Grade 2 & $\begin{array}{l}\text { Moderate: vessel signals in less than half of the } \\
\text { area of the synovium }(<50 \%) \text {. }\end{array}$ \\
\hline Grade 3 & Marked: vessel signals in $>50 \%$ of the synoviun \\
\hline
\end{tabular}


standard deviation (mean $\pm \mathrm{SD}$ ), whereas the Mann-Whitney test was used for quantitative non-parametric variables. A $P$ value of $\leq 0.05$ was considered as statistically significant.

Ethics This study complies with the Declaration of Helsinki and was approved by local ethical research committees; all patients signed a written informed consent.

\section{Results}

\section{Studied groups}

In this case-control study, 109 psoriasis vulgaris patients and 90 healthy controls were included. Clinical varieties of psoriasis patients included $9.2 \%$ plaque psoriasis (skin only); $12.8 \%$ nail psoriasis; $11 \%$ scalp psoriasis; $11.9 \%$ plaque psoriasis plus nail; and $55.1 \%$ plaque psoriasis plus scalp. The mean disease duration was $8.7 \pm 7.17$ years, and the mean PASI score was $14.16 \pm 15.38$. Both patients and controls were age and gender matched $(P>0.05)$. Patients showed statistically significant higher CRP level than controls $(P<0.001)$ (Table 3).

Positive MSUS findings (subclinical synovitis (GSUS $\geqslant 1$, and/or PDUS $\geqslant 1$ ) or enthesitis) present in at least one site were reported in $43(39.5 \%)$ psoriasis patients and in $9(10 \%)$ controls $(P<0.001)$.

Among the scanned 3706 joints of psoriasis patients, subclinical synovitis was found in 51 joints (49 joints with GSUS $\geqslant 1$, and 21 joints with PDUS $\geqslant 1$ ) in 34 patients. This means that of the 49 joints, 19 have also power Doppler $\geqslant 1$ and 2 joints only have power Doppler activity. Almost 872 entheses had been scanned to look for characteristic GSUS/PDUS enthesitis. Among patients, 15 showed evidence of enthesitis that was demonstrated in 22 different sites. Erosions in the second and fifth right $\mathrm{MCP}$ joints have been detected in one patient and confirmed by CT scan.

MSUS was done for 90 controls. A total of 3060 joints were scanned. Positive subclinical synovitis was found in 9 joints ( 8 joints with GSUS $\geqslant 1$, and 2 joints with PDUS $\geqslant 1$ ) in 7 controls. This means one of the joints showed Doppler signals only. For subclinical enthesitis detection, 720 entheses were scanned. Evidence of enthesitis was detected in 5 controls at 7 different sites.

Psoriasis patients showed a statistically significant higher number regarding MSUS positive findings, the number of affected sites for synovitis, GSUS, PDUS, and enthesitis rather than in controls. Moreover, the GSUS scores and PDUS scores were significantly higher in patients rather than in controls $(P$ value $\leq 0.05)$ (Table 4$)$.

Different ultrasonographic pathological findings in psoriatic patients are illustrated in (Fig. 2).

\section{Comparison between psoriatic patients with and without MSUS manifestations according to demographic, clinical, and lab variables}

Psoriatic patients with and without MSUS manifestations did not differ statistically regarding gender, age, duration of psoriasis, and PASI score, although the CPR level was significantly higher in psoriasis patients with MSUS manifestations $12.32 \pm 12.96$ versus $6.88 \pm 13.06$ in those without $(P<0.01)$ (Table 5). Furthermore, the area affected by psoriasis whether the scalp, nail, or skin only did not affect the incidence of MSUS manifestations $(P>0.05)$ (Table 5).

Newly diagnosed PsA patients had higher baseline CRP levels with increased prevalence of baseline MSUS subclinical enthesitis, synovitis with higher GSUS, PDUS scores rather than psoriasis patients without PsA (Table 6).
Table 3 Comparison between psoriasis patients and controls regarding baseline demographic characters, CRP, and MSUS findings

\begin{tabular}{|c|c|c|c|c|c|c|}
\hline & \multicolumn{2}{|c|}{ Patients $(N=109)$} & \multicolumn{2}{|c|}{ Controls $(N=90)$} & \multirow[t]{2}{*}{ Test } & \multirow[t]{2}{*}{$P$ value } \\
\hline & No. & $\%$ & No. & $\%$ & & \\
\hline \multicolumn{7}{|l|}{ Gender } \\
\hline - Female & 65 & 56 & 51 & 44 & $* 0.178$ & 0.673 \\
\hline - Male & 44 & 53 & 39 & 74 & & \\
\hline \multicolumn{7}{|c|}{ MSUS findings } \\
\hline - Positive & 43 & 39.5 & 9 & 10 & $* 22.14$ & $<0.001$ \\
\hline - Negative & 66 & 60.5 & 81 & 90 & & \\
\hline & \multicolumn{2}{|c|}{$($ Mean \pm SD $)$} & \multicolumn{2}{|c|}{$($ Mean \pm SD $)$} & & \\
\hline Age & \multicolumn{2}{|c|}{$41.11 \pm 15.17$} & \multicolumn{2}{|c|}{$39.58 \pm 14.14$} & $* * 4608$ & 0.462 \\
\hline CRP (mg/l) & \multicolumn{2}{|c|}{$9.02 \pm 13.23$} & \multicolumn{2}{|c|}{$2.55 \pm 1.68$} & $* * 2850.5$ & $<0.001 * * *$ \\
\hline
\end{tabular}

$C R P$, C-reactive protein; MSUS, musculoskeletal ultrasound

${ }^{*} \chi^{2}=$ chi-squared test; $* * U=$ Mann-Whitney test 
Table 4 Comparison between psoriasis patients and controls regarding the baseline MSUS findings

\begin{tabular}{lllll}
\hline & $\begin{array}{l}\text { Patients }(N=109) \\
\text { No. }(\%)\end{array}$ & $\begin{array}{l}\text { Controls }(N=90) \\
\text { No. }(\%)\end{array}$ & Test & $P$ value \\
\hline Positive patients for synovitis & $34 / 109(31.2)$ & $7 / 90(7.8)$ & $* 16.522$ & $<0.001$ \\
Joints (NO) positive for MSUS synovitis & $51 / 3706(1.4)$ & $9 / 3060(0.3)$ & $* 31.68$ & $<0.001$ \\
Positive patients for GSUS & $31 / 109(28.4)$ & $6 / 90(6.7)$ & $* 15.44$ & $<0.001$ \\
Joints (NO) positive for GSUS & $49 / 3706(1.3)$ & $8 / 3060(0.3)$ & $* 31.37$ & $<0.001$ \\
Positive patients for PDUS & $17 / 109(15.6)$ & $2 / 90(2.2)$ & $* 10.21$ & 0.001 \\
Joints (NO) positive for PDUS & $21 / 3706(0.6)$ & $2 / 3060(0.07)$ & $* 14$ & $<0.001$ \\
Patients positive for enthesopathy & $15 / 109(13.8)$ & $5 / 90(5.6)$ & $* 3.67$ & 0.05 \\
Enthesopathy (NO) sites diagnosed by MSUS & $22 / 872(2.5)$ & $7 / 720(0.97)$ & $* 6.09$ & 0.01 \\
& Mean \pm SD & Mean \pm SD & & \\
GSUS synovitis score & $0.275 \pm 0.621$ & $0.044 \pm 0.207$ & $* * 4203$ & 0.002 \\
PDUS synovitis score & 0.3110 .676 & $0.044 \pm 0.207$ & $* * 4152$ & 0.001 \\
\hline
\end{tabular}

MSUS, musculoskeletal ultrasound; GSUS, grayscale ultrasound; PDUS, power Doppler ultrasound $* \chi^{2}=$ chi-squared test; $* * U=$ Mann-Whitney test

\section{Follow-up data of MSUS positive patients}

During 2-year clinical follow-up of 109 psoriasis patients, 5 patients missed their follow-up appointments, and 7 out of 41 patients who had positive MSUS findings developed clinical arthritis in the form of hot, tender, and/or swollen joints or enthesis, with or without dactylitis that completed the CASPER classification criteria of PsA [15]. One of these seven cases also developed unilateral sacroiliitis; 2 out of 63 negative MSUS patients also completed the CASPER classification criteria of PsA [15]. The annual incidence of PsA among 104 patients was $4.3 \%$. There was a statistically significant higher association of baseline enthesitis, PDUS, GSUS, and synovitis scores, and higher CPR level with psoriasis patients who developed PsA (Table 6).

Of the 9 PsA patients, $1(11.1 \%)$ has been treated with NSAIDs; 5 patients $(55.6 \%)$ received methotrexate as a conventional disease-modifying anti-rheumatic drug (cDMARDs), and 3 patients $(33.3 \%)$ received biologic bDMARDs (anti-TNF $\alpha$ ).

\section{Discussion}

Recently, MSUS has shown a great impact in the diagnostic era in musculoskeletal diseases, especially for detecting synovitis by using GSUS and PDUS [22, 23], in the assessment of enthesitis [24, 25] and tenosynovitis [26] in different inflammatory arthritis. Several studies demonstrated MSUS abnormalities in joints of psoriatic arthritis patients as well as in patients with psoriasis who did not report pain or swelling at the time of clinical assessment [10, 13, 27-29] with a conclusion that MSUS can proficiently identify subclinical inflamed areas in patients without clinical evidence on examination.

Preclinical phase of PsA can exist in psoriasis prior to the diagnosis of the disease, which is characterized by nonspecific musculoskeletal symptoms, including fatigue and stiffness [30], which may explain subclinical MSUS findings in our study.

In this study, we aimed to detect subclinical synovitis and enthesitis with MSUS in psoriasis patient free from rheumatic manifestation in comparison with healthy controls, with
Fig. 2 Different findings of enthesopathy detected in psoriasis patients. A Calcaneal spur (white arrow); B Thickened Achilles tendon (line measurement), calcifications (vertical arrow), and retrocalcaneal bursa (white arrow); $\mathbf{C}$ Thickened Achilles tendon (white arrow); D Anechoic synovial effusion in suprapatellar pouch of the knee joint (white arrow)

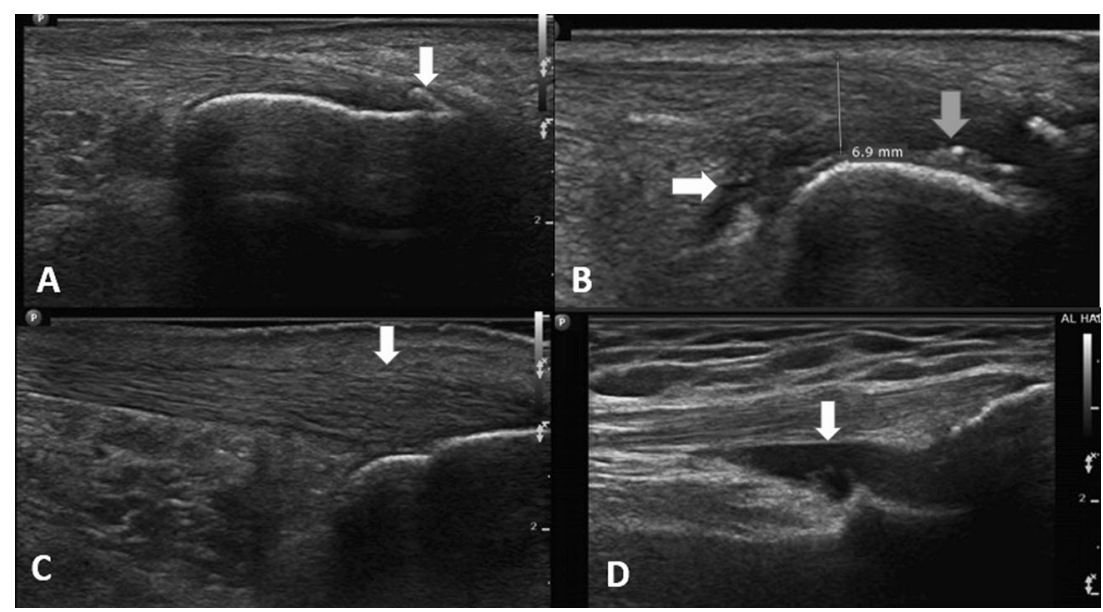


Table 5 Comparison between psoriasis patients with and without MSUS manifestations according to demographic and clinical variables $(N=109)$

\begin{tabular}{|c|c|c|c|c|c|c|}
\hline & \multicolumn{2}{|c|}{$\begin{array}{l}\text { Patients with MSUS manifestations } \\
(N=43)\end{array}$} & \multicolumn{2}{|c|}{$\begin{array}{l}\text { Patients without MSUS manifestations } \\
(N=66)\end{array}$} & \multirow[t]{2}{*}{ Test } & \multirow[t]{2}{*}{$P$ value } \\
\hline & No. & $\%$ & No. & $\%$ & & \\
\hline \multicolumn{7}{|l|}{ Gender } \\
\hline - Female & 24 & 55.8 & 41 & 62.1 & \multirow[t]{2}{*}{$0.43^{*}$} & \multirow[t]{2}{*}{0.51} \\
\hline - Male & 19 & 44.2 & 25 & 37.9 & & \\
\hline \multicolumn{7}{|c|}{ Area of the body affected by psoriasis: } \\
\hline - Psoriasis vulgaris & 3 & 7 & 7 & 10.6 & \multirow[t]{3}{*}{$1.34^{*}$} & \multirow[t]{3}{*}{0.51} \\
\hline - Nail affection & 13 & 30.2 & 14 & 21.2 & & \\
\hline - Scalp affection & 27 & 62.8 & 45 & 68.2 & & \\
\hline Age & \multicolumn{2}{|c|}{$38.53 \pm 13.49$} & \multicolumn{2}{|c|}{$42.78 \pm 16.05$} & $* * 1.47$ & 0.14 \\
\hline Duration of psoriasis & \multicolumn{2}{|c|}{$9 \pm 7.69$} & \multicolumn{2}{|c|}{$8.51 \pm 6.88$} & $* * 0.122$ & 0.903 \\
\hline CRP mg/l & \multicolumn{2}{|c|}{$12.32 \pm 12.96$} & \multicolumn{2}{|c|}{$6.88 \pm 13.06$} & $* * 3.28$ & 0.001 \\
\hline PASI & \multicolumn{2}{|c|}{$14.58 \pm 17.74$} & \multicolumn{2}{|c|}{$13.7 \pm 13.75$} & $* * 0.426$ & 0.67 \\
\hline
\end{tabular}

MSUS, musculoskeletal ultrasound

$* \chi^{2}=$ chi-squared test $; * \mathrm{U}=$ Mann-Whitney test

longitudinal prospective follow-up over 2 years to study PsA incidence and the relation between baseline findings and PsA development.

Subclinical synovitis and enthesitis were detected in $39.5 \%$ of patients and only in $10 \%$ of the control group. Freeston et al. had similar findings, in which MSUS showed power
Doppler signals in $34.7 \%$ of the patients [13]. The current study showed that PDUS, GSUS, subclinical synovitis, and enthesitis were of significantly higher incidence in psoriasis patients than in controls. In a cohort comparing psoriasis patients with and without musculoskeletal signs, the prevalence of MSUS synovitis in asymptomatic joints was $13 \%$ of joints,
Table 6 Comparison between psoriasis patients with and without PsA after a 2 year followup according to their baseline demographic clinical, MSUS, and CRP variables $(N=104)$

\begin{tabular}{|c|c|c|c|c|c|c|}
\hline & \multicolumn{2}{|c|}{$\begin{array}{l}\text { Psoriasis patients } \\
\text { who developed PsA } \\
(N=9)\end{array}$} & \multicolumn{2}{|c|}{$\begin{array}{l}\text { Psoriasis patients who } \\
\text { did not develop PsA } \\
(N=95)\end{array}$} & \multirow[t]{2}{*}{ Test } & \multirow[t]{2}{*}{$P$ value } \\
\hline & No. & $\%$ & No. & $\%$ & & \\
\hline \multicolumn{7}{|l|}{ Gender } \\
\hline - Female & 5 & 55.6 & 57 & 60 & \multirow[t]{2}{*}{$0.06^{*}$} & \multirow[t]{2}{*}{0.79} \\
\hline - Male & 4 & 44.4 & 38 & 40 & & \\
\hline \multicolumn{7}{|c|}{ Area of the body affected by psoriasis } \\
\hline - Psoriasis vulgaris & 0 & 0.0 & 10 & 10.5 & \multirow{3}{*}{$1.16^{*}$} & \multirow{3}{*}{0.56} \\
\hline - Nail affection & 3 & 33.3 & 24 & 25.3 & & \\
\hline \multicolumn{5}{|l|}{ Enthesitis: } & & \\
\hline - Present & 7 & 77.8 & 4 & 4.2 & $47.04 *$ & $<0.001$ \\
\hline - Absent & 2 & 22.2 & 91 & 95.8 & & \\
\hline Age & \multicolumn{2}{|c|}{$31 \pm 9.46$} & \multicolumn{2}{|c|}{$41.56 \pm 15.41$} & $* * 1.93$ & 0.053 \\
\hline Duration of psoriasis & \multicolumn{2}{|c|}{$10.37 \pm 10.12$} & \multicolumn{2}{|c|}{$8.58 \pm 7.03$} & $* * 0.065$ & 0.94 \\
\hline CRP mg/l & \multicolumn{2}{|c|}{$10 \pm 1.45$} & \multicolumn{2}{|c|}{$4.75 \pm 3.2$} & $* * 4$ & $<0.001$ \\
\hline PASI & \multicolumn{2}{|c|}{$14.92 \pm 15.89$} & \multicolumn{2}{|c|}{$7.06 \pm 9.08$} & $* * 1.66$ & 0.09 \\
\hline PDUS score & \multicolumn{2}{|c|}{$2.44 \pm 0.52$} & \multicolumn{2}{|c|}{$0.23 \pm 0.55$} & $6.37 * *$ & $<0.001$ \\
\hline GSUS score & \multicolumn{2}{|c|}{$0.77 \pm 0.97$} & \multicolumn{2}{|c|}{$0.1 \pm 0.34$} & $3.24 * *$ & 0.001 \\
\hline
\end{tabular}

PDUS and GDUS score $\geqslant 1$ is by definition considered synovitis

MSUS, musculoskeletal ultrasound; GSUS, grayscale ultrasound; PDUS, power Doppler ultrasound $* \chi^{2}=$ chi-squared test; $* * U=$ Mann-Whitney test 
while controls showed synovitis in $1.3 \%$, with a statistical significant difference [10].

Scalp and nail psoriasis had been documented in different studies as risk factors for PsA [31, 32]. However, in our study, there was no significant difference between different clinical varieties of psoriasis and GSUS, PDUS, or enthesopathy changes, which is in agreement with other studies [10,28].

Subclinical synovitis and enthesitis had been reported in various studies by different radiological modalities such as MSUS, MRI, and scintigraphy, without any clinical evidence of pain or swelling [10-12, 14, 28, 33, 34]. Naredo et al. found a significantly higher prevalence of subclinical enthesitis and synovitis in psoriasis patients than in controls by MSUS [8].

Some studies investigated CRP in psoriasis. It was remarkably higher in psoriasis patients than in healthy matched controls [35]. These results were in agreement with ours. CRP levels are elevated in patients with psoriasis with or without PsA [36]. Furthermore, our results showed remarkably higher CRP levels in patients with MSUS manifestations than those without $(P<0.001)$. Higher baseline CRP levels in relation to positive MSUS findings and PsA development could be a sign of disease progression. Moreover, some studies showed that CRP levels were higher in PsA patients compared with psoriasis patients without arthritis [37].

One of our patients had erosions with synovitis on the second and fifth right MCP, who developed frank PSA later during follow-up. PsA may develop erosions early, although other observational cohorts stated that PSA patients usually have sustained progressive radiographic damage over time [38, 39]. In addition, erosions documented at the first visit were associated with mortality risk in PsA [40]. Silent erosive joints were documented as not uncommon in Italian patients, who go on to develop a clinically manifested PsA [41]. Ultrasound-detected features of inflammation in the form of grayscale ultrasound and power Doppler activity are associated with the abnormal blood flow of active inflammation in patients with PSA [42].

Up to our knowledge, this is the first Saudi prospective study conducted on psoriasis patients with and without abnormal MSUS, to assess the incidence of PsA among them, and to study the relation of this incidence to the baseline MSUS findings. In our study, the annual incidence of PsA among Saudi psoriasis patients was $4.3 \%$; our incidence is slightly higher than in Eder et al. study [31], in which the annual incidence was $2.7-3.2 \%$ over 8 -year follow-up stud. This difference could be related to different ethnic groups. We have noticed that newly diagnosed PsA patients had higher baseline CRP levels with increased prevalence of baseline MSUS subclinical enthesitis, synovitis with higher GSUS, PDUS scores rather than psoriasis patients without PsA (Table 6).

When using clinical assessment several studies estimated the prevalence of PsA in patients with plaque psoriasis. In a systematic review, the point prevalence of PsA among psoriasis patients ranged from 7 to $26 \%$ [43]. Mease et al. sought to estimate PsA prevalence in patients with plaque psoriasis in 34 dermatology centers in 7 European and North American countries. Of 949 patients evaluated, 285 (30\%) had PsA (95\% confidence interval 27-34) based on rheumatologists' assessment [44]. Villani et al. looked for the prevalence of newly diagnosed PsA in patients with psoriasis at the time they seek medical care. In a review study, seven epidemiological studies and five studies on PsA screening questionnaires were found. The prevalence of undiagnosed PsA was $15.5 \%$ (varying from $4,2 \%-33.6 \%$ ) when all studies were considered and $10.1 \%$ when only epidemiological studies were considered [45]. In a recent Brazilian multicenter study a total of 524 patients with PsA followed in dermatology settings, were evaluated by a rheumatologist. A diagnosis of PsA was documented in 175 patients (33\%), of whom $49 \%$ were newly identified by the rheumatologist [46].

When using MRI for diagnosis of PsA, the figures are higher. In a cross-sectional and longitudinal analysis, Faustini et al. showed that in 55 psoriasis patients free from musculoskeletal manifestations using MRI of the hands, $47 \%$ had at least one inflammatory lesion [47]. Emad et al. detected subclinical synovitis, enthesitis, and/or bone marrow edema changes in 48 psoriasis patients without psoriatic arthritis manifestations using MRI even in 90 out of 96 knees [14].

Our findings are in agreement with another longitudinal study [48], in which high enthesitis, GSUS, and PDUS synovitis scores can predict PSA development in psoriasis patients.

Psoriatic arthritis (PsA) increases the disease burden associated with psoriasis by further diminishing quality of life (QOL), increasing health care costs and cardiovascular risk, and potentially causing progressive joint damage [49]. The presence of PsA influences psoriasis treatment by increasing overall disease complexity and, within the framework of current guidelines and recommendations, requiring the use of conventional diseasemodifying anti-rheumatic drugs or TNF $\alpha$ inhibitors in order to prevent progressive joint damage. Despite its important impact, PsA is still under-diagnosed in dermatology practice. Dermatologists are well positioned to recognize and treat PsA, given that it characteristically presents, on average, 10 years subsequent to the appearance of skin symptoms. Regular screening of psoriasis patients for early evident joint symptoms should be incorporated into daily dermatologic practice $[49,50]$. Early detection and treatment of PsA are of great importance for the patients as these are usually associated with rapid response, regression of radiographic damage, and improved QOL $[9,10$, 48, 49, 51]. A collaboration between dermatologists and rheumatologists is greatly needed to establish earlier PsA diagnoses and adequate multidisciplinary management $[46,47,50]$.

It is still controversial whether we should treat subclinical synovitis with DMARDs like methotrexate or leflunomide or biologicals. In general, close follow-up is recommended until clinical synovitis is seen. When persistent active subclinical synovitis is seen, one may consider to start these treatments 
depending on the severity of the complaints. By early treatment, it may be possible to prevent structural damage. Treatment of patients with early PsA who had higher CRP values shows good efficacy [52].

The strength of our study is that it is a case-controlled study and conducted in a hardly studied ethnic group of Saudi citizens. Almost all relevant joints and entheses were investigated and the follow-up was almost complete. But this study also has some limitations. NSAIDs intake over the counter was not registered, while it can be considered one of the PsA treatments, which might have influenced our results. The fact that it was conducted in one ethnic group only means that the findings cannot be generalized. Although it is one of the largest series of patients published, the sample size is not sufficient to make the results of the incidence generalizable to other settings.

The objective nature of the diagnostic tool used in the study (MSUS) and the plausibility of its findings all support the validity of the conclusions based on this study. Still, longer duration longitudinal studies with larger sample size are needed to confirm our results regarding the incidence of new cases.

\section{Conclusions}

MSUS subclinical synovitis and enthesitis are relatively common findings in psoriasis patients free from musculoskeletal manifestations. The incidence of PsA in the Saudi population maybe slightly higher in comparison with those reported across the world.

Subclinical enthesitis, PDUS, and GSUS synovitis in psoriasis patients are associated with PsA development and can be considered early predictors for PsA. MSUS could be used as a bedside screening tool to detect early PsA in psoriasis patients, especially in those with high CRP. Such patients should be referred to a rheumatologist in an early stage, seeking a better outcome.

\section{Compliance with ethical standards}

This study complies with the Declaration of Helsinki and was approved by local ethical research committees; all patients signed a written informed consent.

\section{Disclosures None.}

Open Access This article is distributed under the terms of the Creative Commons Attribution 4.0 International License (http:// creativecommons.org/licenses/by/4.0/), which permits unrestricted use, distribution, and reproduction in any medium, provided you give appropriate credit to the original author(s) and the source, provide a link to the Creative Commons license, and indicate if changes were made.

Publisher's note Springer Nature remains neutral with regard to jurisdictional claims in published maps and institutional affiliations.

\section{References}

1. Al-Mutairi N, Shabaan D (2016) Effects of tumor necrosis factor $\alpha$ inhibitors extend beyond psoriasis: insulin sensitivity in psoriasis patients with type 2 diabetes mellitus. Cutis 97:235-241

2. Baker H, Golding D, Thompson M (1963) Psoriasis and arthritis. Ann Rheum Dis 2(5371):1527

3. Wright V, Moll JMH (1973) Psoriatic arthritis. Semin Arthritis Rheum 3:55-78

4. Krueger G, Ellis CN (2005) Psoriasis - recent advances in understanding its pathogenesis and treatment. J Am Acad Dermtol 53(suppl 1):S94-S100

5. Fatani MI, Abdulghani MH, Al-Afif KA (2002) Psoriasis in the eastern Saudi Arabia. Saudi Med J 23:213-217

6. Rahman P, Elder J (2005) Genetic epidemiology of psoriasis and psoriatic arthritis. Ann Rheum Dis 64(suppl 2):ii37-ii39

7. Gladman D, Antoni C, Mease P, Clegg DO, Nash P (2005) Psoriatic arthritis: epidemiology, clinical features, course, and outcome. Ann Rheum Dis 64(suppl 2):ii14-ii17

8. Gelfand JM, Gladman DD, Mease PJ Smith N, Margolis DJ, Nijsten T, Stern RS, Feldman SR, Rolstad T (2005) Epidemiology of psoriatic arthritis in the population of the United States. J Am Acad Dermatol 53:573

9. Borman P, Toy GG, Babaoğlu S, Bodur H, Ciliz D, Alli N (2007) A comparative evaluation of quality of life and life satisfaction in patients with psoriatic and rheumatoid arthritis. Clin Rheumatol 26(3):330-334

10. Naredo E, Möller I, de Miguel E, Batlle-Gualda E, Acebes C, Brito E, Mayordomo L, Moragues C et al (2011) High prevalence of ultrasonographic synovitis and enthesopathy in patients with psoriasis without psoriatic arthritis: a prospective case-control study. Rheumatology 50:1838-1848

11. Gisondi P, Tinazzi I, El-Dalati G, Gallo M, Biasi D, Barbara LM, Girolomoni G (2008) Lower limb enthesopathy in patients with psoriasis without clinical signs of arthropathy: a hospital-based case-control study. Ann Rheum Dis 67:26-30

12. De Filippis L, Caliri A, Lo Gullo R, Bartolone S, Miceli G, Cannavò SP, Borgia F, Basile G, Aloisi G et al (2005) Ultrasonography in the early diagnosis of psoriasis-associated enthesopathy. Int J Tissue React 27:159-162

13. Freeston JE, Coates LC, Nam JL, Moverley AR, Hensor EM, Wakefield RJ, Emery P, Helliwell PS, Conaghan PG (2014) Is there subclinical synovitis in early psoriatic arthritis? A clinical comparison with gray-scale and power Doppler ultrasound. Arthritis Care Res 66:432-439

14. Emad Y, Ragab Y, Gheita T, Anbar A, Kamal H, Saad A, Darweesh H, El-Shaarawy N, Azab A, Ismail A, Rasker JJ, and Knee Enthesitis Working Group (2012) Knee enthesitis and synovitis on magnetic resonance imaging in patients with psoriasis without arthritic symptoms. J Rheumatol 39:1979-1986

15. Taylor W, Gladman D, Helliwell P et al (2006) Classification criteria for psoriatic arthritis: development of new criteria from a large international study. Arthritis Rheum 54:2665-2267

16. Scott DL, Houssien DA (1996) Joint assessment in rheumatoid arthritis. Br J Rheumatol 35(Suppl 2):14-18

17. Heuft-Dorenbosch L, Spoorenberg A, van Tubergen A, Landewe $\mathrm{R}$, van der Tempel H, Mielants H, Dougados M, van der Heijde D (2003) Assessment of enthesitis in ankylosing spondylitis. Ann Rheum Dis 62:127-132

18. Langley RG, Ellis CN (2004) Evaluating psoriasis with psoriasis area and severity index, psoriasis global assessment, and lattice system physician's global assessment. J Am Acad Dermatol 51: 563-569

19. Terslev L, Naredo E, Iagnocco A, Balint PV, Wakefield RJ, Aegerter P, Aydin SZ, Bachta A, Hammer HB, Bruyn GAW, 
Filippucci E, Gandjbakhch F, Mandl P, Pineda C, Schmidt WA, D'Agostino MA, on behalf of the Outcome Measures in Rheumatology Ultrasound Task Force (2014) Defining enthesitis in spondyloarthritis by ultrasound: results of a Delphi process and of a reliability reading exercise. Arthritis Care Res (Hoboken) 66: $741-748$

20. Szkudlarek M, Court-Payen M, Jacobsen S, Klarlund M, Thomsen HS, Østergaard M (2003) Interobserver agreement in ultrasonography of the finger and toe joints in rheumatoid arthritis. Arthritis Rheumatol 48:955-962

21. Naredo E, Collado P, Cruz A, Palop MJ, Cabero F, Richi P, Carmona L, Crespo M (2007) Longitudinal power Doppler ultrasonographic assessment of joint inflammatory activity in early rheumatoid arthritis: predictive value in disease activity and radiologic progression. Arthritis Care Res 57:116-124

22. Schmidt W, Völker L, Zacher J, Schläfke M, Ruhnke M, GromnicaIhle E (2000) Colour Doppler ultrasonography to detect pannus in knee joint synovitis. Clin Exp Rheumatol 18:439-444

23. Naredo E, Möller I, Cruz A, Carmona L, Garrido J (2008) Power Doppler ultrasonographic monitoring of response to anti-tumor necrosis factor therapy in patients with rheumatoid arthritis. Arthritis Rheumatol 58:2248-2256

24. Kamel M, Eid H, Mansour R (2003) Ultrasound detection of heel enthesitis: a comparison with magnetic resonance imaging. J Rheumatol 30:774-778

25. Kamel M, Eid H, Mansour R (2004) Ultrasound detection of knee patellar enthesitis: a comparison with magnetic resonance imaging. Ann Rheum Dis 63:213-214

26. Vlad V, Berghea F, Micu M, Varzaru L, Bojinca M, Milicescu M, Ionescu R, Naredo E (2015) Tenosynovitis US scoring systems follow synovitis and clinical scoring systems in RA and are responsive to change after biologic therapy. Med Ultrasonogr 17:352-360

27. Sturrock RD (2009) Clinical utility of ultrasonography in spondyloarthropathies. Curr Rheumatol Rep 11:317-320

28. Delle Sedie A, Riente L, Filippucci E, Scirè CA, Iagnocco A, Meenagh G, Gutierrez M, Valesini G, Montecucco C, Grassi W, Bombardieri S (2011) Ultrasound imaging for the rheumatologist. XXXII. Sonographic assessment of the foot in patients with psoriatic arthritis. Clin Exp Rheumatol 29:217-222

29. Riente L, Delle Sedie A, Filippucci E, Iagnocco A, Sakellariou G, Talarico R, Carli L, Di Geso L, Ceccarelli F, Bombardieri S (2013) Ultrasound imaging for the rheumatologist XLV. Ultrasound of the shoulder in psoriatic arthritis. Clin Exp Rheumatol 31:329-333

30. Eder L, Polachek A, Rosen CF, Chandran V, Cook R, Gladman DD (2017) The development of psoriatic arthritis in patients with psoriasis is preceded by a period of nonspecific musculoskeletal symptoms: a prospective cohort study. Arthritis Rheumatol. 69:622-629

31. Eder L, Haddad A, Rosen CF, Lee KA, Chandran V, Cook R, Gladman DD (2016) The incidence and risk factors for psoriatic arthritis in patients with psoriasis: a prospective cohort study. Arthritis Rheumatol 68:915-923

32. Wilson FC, Icen M, Crowson CS, McEvoy MT, Gabriel SE, Kremers HM (2009) Incidence and clinical predictors of psoriatic arthritis in patients with psoriasis: a population-based study. Arthritis Rheum 61:233-239

33. Bonifati C, Elia F, Graceffa D, Ceralli F, Maiani E, De Mutiis C, Solivetti FM (2013) Ultrasound detects occult entheseal involvement in early psoriatic arthritis independently of clinical features and psoriasis severity. Clin Exp Rheumatol 31:219-224

34. Gutierrez M, Filippucci E, De Angelis R, Salaffi F, Filosa G, Ruta S, Bertolazzi C, Grassi W (2011) Subclinical entheseal involvement in patients with psoriasis: an ultrasound study. Semin Arthritis Rheum 40:407-412

35. Vadakayil AR, Dandekeri S, Kambil SM, Ali NM (2015) Role of Creactive protein as a marker of disease severity and cardiovascular risk in patients with psoriasis. Indian Dermatol Online J 6:322-325
36. Strober B, Teller C, Yamauchi P, Miller JL, Hooper M, Yang YC, Dann F (2008) Effects of etanercept on C-reactive protein levels in psoriasis and psoriatic arthritis. Br J Dermatol 159:322-330

37. Chandran V, Cook RJ, Edwin J, Shen H, Pellett FJ, Shanmugarajah S, Rosen CF, Gladman DD (2010) Soluble biomarkers differentiate patients with psoriatic arthritis from those with psoriasis without arthritis. Rheumatology 49:1399-1405

38. Gladman DD, Farewell VT, Nadeau C (1995) Clinical indicators of progression in psoriatic arthritis $(\mathrm{PsA})$ : multivariate relative risk model. J Rheumatol 22:675-679

39. Bond SJ, Farewell VT, Schentag CT, Gladman DD (2007) Predictors for radiological damage in psoriatic arthritis. Results from a single centre. Ann Rheum Dis 66:370-376

40. Gladman DD, Farewell VT, Husted J, Wong K (1998) Mortality studies in psoriatic arthritis. Results from a single centre. II. Prognostic indicators for mortality. Arthritis Rheum 41:1103-1110

41. D'Agostino CPL, D'Amico E, Petricca EPA (2003) Asymptomatic erosive peripheral psoriatic arthritis: a frequent finding in Italian patients. Rheumatology (Oxford) 42:909-911

42. Gutierrez M, Filippucci E, De Angelis R, Filosa G, Kane D, Grassi W (2010) A sonographic spectrum of psoriatic arthritis: "the five targets". Clin Rheumatol 29:133-142

43. Prey S, Paul C, Bronsard V, Puzenat E, Gourraud PA, Aractingi S, Aubin F, Bagot M, Cribier B, Joly P, Jullien D, Maitre ML, RichardLallemand MA, Ortonne JP (2010) Assessment of risk of psoriatic arthritis in patients with plaque psoriasis: a systematic review of the literature. J Eur Acad Dermatol Venereol 24(Suppl 2):31-35 Review

44. Mease PJ, Gladman DD, Papp KA, Khraishi MM, Thaçi D, Behrens F, Northington R, Fuiman J, Bananis E, Boggs R, Alvarez D (2013) Prevalence of rheumatologist-diagnosed psoriatic arthritis in patients with psoriasis in European/North American dermatology clinics. J Am Acad Dermatol 69:729-735

45. Villani AP, Rouzaud M, Sevrain M, Barnetche T, Paul C, Richard MA, Beylot-Barry M, Misery L, Joly P, Le Maitre M, Aractingi S, Aubin F, Cantagrel A, Ortonne JP, Jullien D (2015) Prevalence of undiagnosed psoriatic arthritis among psoriasis patients: systematic review and meta-analysis. J Am Acad Dermatol 73:242-248

46. Ranza R, Carneiro S, Qureshi AA, Martins G, Rodrigues JJ, Romiti R, Barros TB, Carneiro J, Sampaio AL, Grynszpan R, Markus J, Pinto RM, Goldenstein-Schainberg C (2015) Prevalence of psoriatic arthritis in a large cohort of Brazilian patients with psoriasis. J Rheumatol 42:829-834

47. Faustini F, Simon D, Oliveira I, Kleyer A, Haschka J, Englbrecht M, Cavalcante AR, Kraus S, Tabosa TP, Figueiredo C, Hueber AJ, Kocijan R, Cavallaro A, Schett G, Sticherling M, Rech J (2016) Subclinical joint inflammation in patients with psoriasis without concomitant psoriatic arthritis: a cross-sectional and longitudinal analysis. Ann Rheum Dis 75:2068-2074

48. El Miedany Y, El Gaafary M, Youssef S, Ahmed I, Nasr A (2015) Tailored approach to early psoriatic arthritis patients: clinical and ultrasonographic predictors for structural joint damage. Clin Rheumatol 34:307-313

49. Boehncke WH, Menter A (2013) Burden of disease: psoriasis and psoriatic arthritis. Am J Clin Dermatol 14:377-388 Review

50. Helliwell PS (2015) Screening for psoriatic arthritis in people with psoriasis. J Rheumatol 42:736-738

51. Acquacalda E, Albert C, Montaudie H, Fontas E, Danre A, Roux CH, Breuil V, Lacour JP, Passeron T, Ziegler LE (2015) Ultrasound study of entheses in psoriasis patients with or without musculoskeletal symptoms: a prospective study. Joint Bone Spine 82:267-271

52. Scarpa R, Peluso R, Atteno M, Manguso F, Spanò A, Iervolino S, di Minno MND, Costa L, del Puente A (2008) The effectiveness of a traditional therapeutical approach in early psoriatic arthritis: results of a pilot randomised 6-month trial with methotrexate. Clin Rheumatol 27:823-826 